\section{BIBLIOTECONOMIA E AS CONTRADIÇÕES DO SOCIAL}

Gabrielle Francinne de Souza Carvalho Tanus*

\begin{abstract}
A análise e a relação discursiva da Biblioteconomia podem ser empreendidas a partir de diferentes correntes de pensamento. Neste trabalho nos concentramos nos discursos da Biblioteconomia com as Ciências Sociais e Humanas; em particular, com o pensamento marxista e crítico. Essa vertente nomeada de "contradições do social" busca desvelar as contradições, conflitos e interesses presentes na sociedade. Para essa discussão, os discursos de Brown César, Rendón Rojas, Almeida Júnior e Milanesi são convocados e tensionados. Estes autores trazem elementos em seus discursos que possibilitam tal relação, seja no todo ou em partes, tendo em vista que os dois primeiros podem ter seus discursos também associados a outras correntes de pensamentos como, por exemplo, "ordenamento do social" e "construção do social" respectivamente. A compreensão dos saberes que conformam parte do discurso da Biblioteconomia possibilita uma visão mais aprofundada desse campo científico, trazendo luz, também, ao contexto mais amplo das Ciências Sociais e Humanas, onde se insere como modalidade específica do pensamento.
\end{abstract}

Palavras-chaves: Biblioteconomia. Correntes de pensamento. Ciências Sociais e Humanas. Análise do discurso.

\footnotetext{
* Doutora em Ciência da Informação pela Universidade Federal de Minas Gerais, Brasil. Bibliotecária da Escola de Ciência da Informação da Universidade Federal de Minas Gerais, Brasil.

E-mail: gfrancinne@gmail.com.
}

\section{INTRODUÇÃO}

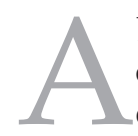

Biblioteconomia é um campo do conhecimento secular associada ao plano empírico da existência das primeiras bibliotecas ainda na Antiguidade, trazendo em seu desenvolvimento três grandes momentos, nomeados de fase pré-científica, protocientífica e científica (PULIDO; MORRILAS, 2010). Esta última - fase científica - tem sua origem vinculada aos acontecimentos no século XIX, dentre eles no plano da ciência, o desenvolvimento e a consolidação do positivismo - primeira corrente de pensamento das Ciências Sociais, inaugurada por Auguste Comte e continuada por Émile Durkheim, que delineou o "fato social" como objeto de estudo da Sociologia, considerado também "pai" do funcionalismo, uma vertente de pensamento preocupada com a ordem social e com as funções desempenhadas para o bom funcionamento da sociedade. De modo geral, o positivismo objetivava um método único, o mesmo das ciências naturais e exatas às ciências sociais; atribuía um papel exterior ao indivíduo inserido em uma realidade estável; busca de regularidades e leis constantes; tendo como guia os pressupostos da matemática e a observação dos fenômenos (COLLINS, 2009).

Num primeiro momento, no que se relaciona à Biblioteconomia, López (2010) destaca que o positivismo foi importante para a constituição da cientificidade da Biblioteconomia, atrelada a uma "vontade de serviço", relacionada ao surgimento da biblioteca pública, no século XIX. Contudo, sem adentrar nesse processo histórico de constituição das bibliotecas e da Biblioteconomia, salienta-se que a estrutura positivista do pensamento possibilitou àquela uma elevação como uma "ciência positiva" 
(ARAÚJO, 2013). Ademais, a influência mais marcante do positivismo na Biblioteconomia, no plano das práticas e do empírico, revelase a partir dos esquemas de catalogação e classificação, que buscavam a representação do conhecimento, bem como o pensamento voltado "para dentro", aos documentos e às coleções custodiadas nas bibliotecas (ARAÚJO, 2013). Entretanto, sem adentrar no desenrolar das influências positivistas e do funcionalismo, que conformam as características da corrente de pensamento "ordenamento do social", neste trabalho, concentramos em explorar uma segunda corrente de pensamento das Ciências Sociais e Humanas, pautada pelo conflito e pela "contradição do social".

Assim, o desvelamento da realidade social a partir dos conflitos e das contradições das classes sociais, em especial, da sociedade capitalista em desenvolvimento, foi preocupação inicial de Karl Marx (1818-1883). Este pensador, ao lado de Comte (1798-1857), Durkheim (1858-1917) e Max Weber (1864-1920), forma a tríade dos autores clássicos da Sociologia, todavia, de modo diferente daqueles; o segundo representante do Positivismo Sociológico e o terceiro da Sociologia Compreensiva, Marx e seu companheiro Friedrich Engels (18201895), precursores da Sociologia do Conflito, detiveram-se na compreensão das sociedades por meio das forças produtivas, das relações sociais de produção, do materialismo histórico, bem como buscaram compreender a dinâmica do mercado na sociedade capitalista, fetichismo da mercadoria, a relação oferta-demanda, maisvalia, o trabalho e a alienação do trabalhador, entre muitos outros conceitos e aspectos (filosófico, econômico, histórico) (SELL, 2009; BOTTOMORE, 1988).

Acredita-se que a análise discursiva dos saberes da Biblioteconomia possibilitaria maior compreensão desse campo, que ainda parece pouco explorado teoricamente, dentro de um contexto em que vários discursos diferentes são tensionados. Salienta-se que o extrato deste trabalho faz parte da pesquisa de doutorado em desenvolvimento no programa de pós-graduação em Ciência da Informação (UFMG), cujo objetivo geral da pesquisa consiste na análise dos discursos da Biblioteconomia produzidos por autores norte-americanos, brasileiros e mexicanos, a fim de compreender as práticas discursivas deste campo científico, bem como estabelecer uma relação com o pensamento das Ciências Sociais e Humanas. Faz parte do corpus, um conjunto de discursos produzidos no século XX-XXI, os quais são formados por sua vez, por três livros de cada um dos países supracitados ${ }^{1}$ para compor a análise do discurso, que tem como fundamento o momento arqueológico de Michel Foucault (2000).

A leitura e análise dos livros possibilitaram uma relação discursiva com as Ciências Sociais e Humanas, representadas a partir de três categorias propostas por Lallement (2008). Os livros centrais deste momento de apresentação das análises de autoria de Milanesi (1986) e Almeida Júnior (1997) se destacam, na íntegra, dentro da perspectiva da "contradição do social", trazendo à luz discussões inerentes a essa corrente de pensamento. Conforme Araújo (2014), as produções da Biblioteconomia guiadas por uma manifestação marxista fazem parte de um contexto específico - processo de redemocratização, pós-ditaduras militares nos países do terceiro mundo - corroborandose, assim, o contexto de produção desses dois livros. Os livros de Brown César (2000) e Rojas (2005) presentes nesta discussão trazem certos elementos que possibilitam a inserção dentro da categoria em foco; a figura central para esse enlace parte da concepção de documento apresentada pelos autores.

Contudo, ambos os livros trazem outras perspectivas de análise; Brown César (2000) sob o aporte da teoria dos sistemas de Niklas Luhmann volta-se à apreensão do sistema de gestão documental, partindo de uma visão funcionalista, trazendo em sua completude características que mais se aproximam de um "ordenamento social". Rojas (2005) caminha na direção oposta,

\footnotetext{
Os livros selecionados são: "Introdução à ciência da biblioteconomia" de Pierce Butler; "Expect more: demanding better libraries for today's complex Word" de David Lankes; "The foundations of education for librarianship" de Jesse Shera (Estados Unidos da América). "Estudios epistemológicos de bibliotecología” de Héctor Guilhermo Alfaro López; "Elementos para uma teoria bibliotecária" de Javier Brown César; "Bases teóricas y filosóficas de la Bibliotecología” de Miguel Ángel Rendón Rojas (México). "Sociedade e Biblioteconomia" de Oswaldo Almeida Júnior; "Introdução à biblioteconomia" de Edson Nery da Fonseca; "Ordenar para desordenar: centros de cultura e bibliotecas públicas" de Luiz Milanesi (Brasil). Tais autores foram selecionados a partir da temática de suas obras que circundam os aspectos teóricos e epistemológicos da Biblioteconomia. O foco consiste em analisar discursivamente a Biblioteconomia como um campo científico, sendo excluídas as obras que, mesmo teóricas, abordam um determinado assunto ou temática que compõem a Biblioteconomia, excluindo também as seguintes tipologias documentais: artigos, teses e dissertações.
} 
isto é, a partir de um olhar filosófico, em especial da Hermenêutica, discute o sujeito em seu processo de devir e a importância em acessar a instituição informativa documental e o "mundo da informação", portanto, seu olhar está mais direcionado a uma "construção do social". Os demais livros selecionados para a pesquisa (BUTLER, 1971; SHERA, 1990; LANKES, 2015; LÓPEZ, 2010; FONSECA, 2007) e analisados em outros momentos não trazem elementos para uma discussão voltada à "contradição do social". Destarte, concentramos num primeiro momento no entendimento, sobretudo do pensamento marxista e do pensamento crítico, de tal corrente de pensamento, em que "a ordem social é constituída por grupos e indivíduos que tentam impor seus próprios interesses sobre os outros, sendo que podem ou não irromper conflitos abertos nessa luta para obter vantagem" (COLLINS, 2009, p. 49) para, depois, apresentar/ analisar e tensionar os discursos específicos da Biblioteconomia.

\section{CONTRADIÇÕES DO SOCIAL}

Marx e Engels, no livro "Ideologia alemã", escrito entre os anos de 1845-1846, analisaram as sociedades escravocratas, feudais e capitalistas, sob o olhar do materialismo dialético e histórico, que parte da concepção materialista da realidade - condição da vida material da sociedade em diferentes momentos da história. As forças materiais são responsáveis pela formação da consciência social por meio da vida produtiva, do trabalho do homem, determinando as ideias e concepções. Uma trajetória histórica que é resultante da ação do homem, de um sujeito histórico que constrói a realidade - marcada pelos confrontos entre as classes sociais, "uma exploração do homem pelo homem". As estruturas econômicas configuram, num primeiro plano de análise, não mais as ideias ou o plano intelectual, postura central do idealismo alemão. Assim, foi atribuída à dialética, proposta por Hegel, uma interpretação materialista, invertendo a análise de caráter idealista. Marx e Engels, contudo, conservaram o caráter antagônico da dialética, que permite olhar os fenômenos sociais e humanos historicamente produzidos, apontando as contradições constitutivas da vida social que resultam na negação e superação de determinada ordem (OLIVEIRA; QUINTANEIRO, 2010).

A observação da realidade inclui a análise da infraestrutura e da superestrutura, sendo que a primeira se relaciona à base econômica ou material e exerce influência na segunda, que compreende as instituições jurídicas, políticas (leis, Estado), religião, cultura e o plano ideológico. As classes sociais são fundadas sob uma base material de natureza econômica que demarca interesses diferentes, refletindo as circunstâncias sociais e ideologias distintas. O princípio básico do materialismo é o de que a consciência humana repousa sobre condições materiais, sem as quais ela não existiria, sendo a consciência um produto social. Marx e Engels apresentam que, em cada época as ideias das classes dominantes prevaleceram, pois são elas que detêm os mecanismos de controle e de produção - as ideias refletem interesses econômicos das classes de maneira idealizada. Assim, "as ideias, enquanto ideologia, servem a um duplo propósito, pois, ao mesmo tempo que, promovem uma exaltação de quem as proclama, também agem como um manto que faz com seus interesses adquiram forma idealizada, conquistando deferências" (COLLINS, 2009, p. 64).

Para Marx, a ideologia funciona como uma "falsa consciência", uma concepção invertida da realidade, ou seja, uma visão errônea da sociedade que serve à classe dominante para se manter e perpetuar seus valores aos outros. Essa definição de caráter negativo atende aos interesses de uma minoria, levando os homens a não se perceberem como sujeitos da práxis, também construtores de ideias e valores. No plano da economia, a divisão entre as classes é também reforçada pela diferença entre aquilo que o trabalhador gera com a sua força de trabalho e o real valor que essa força de trabalho é paga, gerando um capital excedente expresso na forma de "mais-valia" e de lucro ao capitalista. Os princípios como liberdade e igualdade só seriam possíveis com a abolição do capital e por meio da revolução do proletariado, o que garantiria a emancipação em relação à dominação capitalista e à instauração de um novo regime, o comunismo - uma superação final da alienação humana; conquista do poder político pelo proletariado; formação do proletariado em classe; derrubamento da dominação burguesa; abolição da relação de propriedade (MARX, 1997). 
No "Manifesto do Partido Comunista" Marx deixa claro que, toda a luta de classes é uma luta política, o capital não é, portanto, um poder pessoal, mas sim social, devendo ser transformado em propriedade comum, uma propriedade social que não atenda mais os interesses de uma divisão de classes demarcada pela posse, pela propriedade, pelo capital. O capital exerce papel central na sociedade capitalista, regida pelo mercado que opera na relação oferta-demanda e pelo próprio sistema instaurado pelo capital, tendo como força central a capacidade de organizar a vida social em torno do mercado, que, por sua vez, reestrutura-se em torno da lógica da troca mercantil. O mercado além da função de troca funciona também como mecanismo de aprofundamento das desigualdades e da distribuição de bens de acordo com as classes sociais, que são de duas ordens: a capitalista e o proletariado. Para Marx, os capitalistas detêm os meios de produção, as máquinas e os instrumentos necessários, inclusive o capital, enquanto o proletário é aquele que, por não deter os meios de produção, vende sua força de trabalho em troca de um salário (um salário mínimo, capaz de manter vivo o operário como operário). A propriedade constitui, portanto, um divisor social entre as classes sociais "a condição essencial à existência e para a dominação da classe burguesa é a acumulação da riqueza nas mãos de privados, a formação e multiplicação do capital; a condição do capital é trabalho assalariado" (MARX, 1997, p.49).

Em relação à mercadoria, unidade elementar da sociedade capitalista, Marx aborda dois tipos de valor que assumem o produto da força de trabalho do homem: valor de uso e valor de troca, ambos trabalhados no livro "O capital" (volume 1). O primeiro se relaciona ao que pode ser feito, efetivamente, com a mercadoria, um valor que se efetiva no consumo, enquanto o valor de troca envolve o valor da mercadoria no mercado. Este valor é calculado segundo o tempo e acúmulo de trabalho socialmente necessário para tal produção. $\mathrm{O}$ próprio trabalho, atividade essencialmente humana de transformação do mundo natural passa a ser uma mercadoria; é atribuído um valor à força produtiva, sendo, por sua vez, regulado pela oferta-demanda, "se a oferta é muito maior do que a demanda, uma parte dos operários mergulha na mendicância ou morre de inanição" (MARX, 1974). Ainda, segundo Marx, "o capital, assim como o trabalho assalariado é um relação social de produção, é um forma histórica de distribuição das condições de produção, resultante de um processo de expropriação e concentração de propriedade" (OLIVEIRA; QUINTANEIRO, 2010, p. 47). Outro desdobramento da mercadoria é o fetichismo da mercadoria, que é um ocultamento do trabalho social na aparência material, o que leva a uma incapacidade dos produtores de perceber que, através da troca dos frutos de seus trabalhos no mercado, são eles próprios que estabelecem uma relação social.

Muitos foram os desdobramentos do pensamento marxista quanto a esta questão da ideologia e ação do Estado; Althusser (1970) retoma Marx e à psicanálise para ampliar e definir dois tipos de aparelhos do estado: "Aparelho Ideológico do Estado", que funciona por meio da ideologia ao lado do "Aparelho Repressivo do Estado", que atua por meio da força, da violência - pelo menos no limite (porque a repressão, por exemplo, administrativa pode revestir-se de formas não físicas). Aparelhos que não se confundem, o primeiro (na sua dispersão aparente) se revela majoritariamente, sendo da ordem do domínio do privado, enquanto, pelo contrário, o segundo aparelho é do domínio público. Contudo, diz Althusser (1970, p. 46) "instituições privadas podem perfeitamente funcionar como aparelhos ideológicos do estado", o que importa é o seu funcionamento. Visão diferente de Marx que via o Estado como um aparelho repressivo, um instrumento de dominação de uma classe sobre a outra, uma espécie de "comitê executivo da burguesia", figurada no Estado, administração, exército, polícia, tribunais, prisões, etc. (MARX, 1997).

O pensamento marxista é retomado por vários seguidores ao longo do século XX-XXI, sob diversas denominações: marxismo-leninismo, marxismo ortodoxo, marxismo italiano, austromarxismo (teóricos austríacos) e marxismorevisionismo. E também diferentes teóricos filiados à Escola de Frankfurt, que têm como base Marx e o pensamento crítico, cujos princípios fundamentais são: orientação à emancipação e ao comportamento crítico (NOBRE, 2011). Em particular, nas discussões do fetichismo nas 
artes, na música, no cinema, nas expressões do conhecimento estão os autores daquela Escola, que traz também outros embates, tais como: sociedade do consumo, do espetáculo, cultura de massa, indústria cultural, etc., radicalizando um capitalismo posterior a Marx. Segundo Collins (2008) uma inspiração marxista e uma abordagem freudiana são combinadas num vasto projeto de pesquisa de campo para tentar compreender os mecanismos de dominação e da submissão à autoridade a fim de construir uma teoria crítica que vai além de Marx.

Esse conjunto diverso de pesquisadores que compartilhavam do espírito crítico, tendo por referência a obra de Marx, divergiam também entre si, “[...] não só porque a própria obra de Marx se presta a interpretação divergentes, mas também pelo fato de que as maneiras de utilizar Marx para compreender o tempo são diversas" (NOBRE, 2010, p. 16). A expressão "teoria crítica", em oposição à "teoria tradicional", se associa ao texto fundador "Teoria Tradicional e Teoria Crítica", escrito em 1937, por Max Horkheimer, publicado na revista Zeitschrift für Sozialforschung do Instituto de Pesquisa Social, criado em 1923, cujo objetivo era o de promover, em âmbito universitário, investigações científicas a partir do marxismo (NOBRE, 2011). Neste texto, Horkheimer (1980) questionou a pretensa neutralidade das ciências humanas e sociais, que procurava seguir o modelo das "bem sucedidas" ciências naturais, com apreensões de fatos externos e métodos empíricos e matemáticos, uma clara crítica ao modelo positivista. As teorias tradicionais separavam o sujeito do objeto de pesquisa, não questionando, ao longo do processo científico a subjetividade inerente e o caráter histórico da ciência e das relações sociais, promovendo uma desconexão com a realidade e uma mera constatação e previsão segundo probabilidades (HORKHEIMER, 1980a).

Horkheimer (1980) esclarece que a teoria dentro dessa perspectiva tradicional é vista como uma categoria coisificada, a-histórica e, por conseguinte, ideológica. O sujeito é visto pelas teorias tradicionais como isento das relações históricas de sua base material, que conformam os processos de produção e reprodução de sua vida por meio do trabalho e análises sob condições econômicas, sociais, políticas e intelectuais, não se podendo esquecer que "os cientistas e a ciência estão atrelados ao aparelho social" (HORKHEIMER, 1980). A ciência é um produto social, feita sob condições históricas, não é, portanto, autônoma e independente. Assim como o mundo social é produto da práxis social "o que percebemos no nosso ambiente, as cidades, povoados, campos e bosques trazem em si marcas do trabalho" (HORKHEIMER, 1980, p. 39), o próprio homem traz as marcas das relações sociais com outros indivíduos e com a natureza; o processo de vida social é algo situado historicamente.

Dito isso, o questionamento do caráter parcial de olhar a realidade e de uma pretensa neutralidade dos fatos é objeto de crítica da teoria crítica, colocando no centro das discussões a categoria da totalidade análises macrossociológicas -, ressaltando a "relação com o todo", inclusive com o tempo presente de desenvolvimento da teoria, que corresponde à contextualização de conceitos dentro da teoria e um comprometimento com a práxis - "a qual serve e na qual está inserida" (HORKHEIMER, 1980, p. 68). A superação, de um lado teoria e de outro a prática foi demonstrada por Marx, que se posicionou contra essa separação entre as categorias: pensamento/conhecer e a realidade/agir. Marx salientou a importância das contradições e dos conflitos nas relações sociais, que constitui a base do método dialético e do materialismo histórico. Tal conceito foi retomado por Horkheimer, que nomeia de materialismo interdisciplinar, chamando atenção à interdisciplinaridade e para pensar a sociedade de modo mais amplo, conferindo um sentido positivo à especialização, antes enclausurada em disciplinas. Horkheimer (1980) apresenta ainda, na esteira da influência marxista e, diferentemente do modelo da teoria tradicional que nomeia, ora de "ciências burguesas", o posicionamento da teoria crítica que almeja emancipar e transformar o homem e o todo a sua volta, o pensamento que se pretende acomodar em si mesmo, repousando numa verdade qualquer, nada tem a ver com a teoria crítica e com a ação transformadora.

Ademais, Horkheimer (1980) reconfigura a concepção da sociedade não mais como resultado de uma ação espontânea de indivíduos, mas sim como consequência da totalidade da ação social dos indivíduos, os quais estabelecem 
relações sociais dentro de uma forma histórica de organização social. Nesse mesmo caminho, Marx havia definido que a sociedade é um produto da ação recíproca entre os homens, na qual se estrutura em torno das forças produtivas e das relações sociais de produção (OLIVEIRA; QUINTANEIRO, 2010). Segundo esses autores, a força produtiva é definida a partir da relação do homem com a natureza, enquanto o segundo aborda as relações entre os homens e os processos produtivos. Assim, "a ação dos indivíduos sobre a natureza é expressa no conceito de forças produtivas $[. .$.$] " \mathrm{e}$ "o conceito de relações sociais de produção refere-se às formas estabelecidas de distribuição dos meios de produção e do produto e o tipo de divisão social do trabalho em uma dada sociedade e num período histórico determinado" (OLIVEIRA; QUINTANEIRO, 2010, p. 35).

A teoria crítica retoma o conceito de alienação de Marx para discutir o papel e a ação da indústria cultural, um sistema político e econômico que alienava o sujeito por meio da comunicação dos sistemas de massa. Retornando a Marx, a alienação está vinculada ao trabalho, e surge a partir da divisão social do trabalho e do aparecimento da propriedade privada; o homem, nesse processo, não se percebe no produto de seu trabalho, não é dono de seu trabalho, configurando-se como alheio à realidade social e numa clara cisão entre o trabalho e o produto de seu trabalho, que pertence a outro. Esse estranhamento, separação do homem com o trabalho ocorre, então, em quatro esferas: 1) no produto de seu trabalho e o capital; 2) na própria atividade; 3) no ser genérico do homem; 4) relação com outros homens; uma contradição entre a realização do trabalho e a negação provocada por ele, havendo um distanciamento da realidade e do "eu"; Marx escreve - "não é apenas o trabalho que é dividido, subdivido e repartido entre diversos indivíduos. É o indivíduo, ele mesmo, que é retalhado e metamorfoseado em mola automática de uma operação exclusiva".

O termo indústria cultural foi utilizado na obra "Dialética do Esclarecimento", escrito por Horkheimer e Adorno, publicado em 1947. Neste livro, os autores discorrem que a indústria cultural tornava os sujeitos dependentes, com gostos padronizados, o que alienava os homens e subsumia a valorização da cultura em detrimento de uma ideologia imposta às pessoas. Freitag (1994) aponta, também, que esta obra marca a ruptura com a concepção Kantiana da razão como sendo libertadora, a qual é asfixiada pelas relações de produção capitalista, bem como pelo esgotamento da razão, demonstrada pelas barbáries, como as guerras mundiais e regimes totalitários do século XX. Vale à pena ressaltar que não caberia, aqui, enfocar os múltiplos modelos críticos desenvolvidos pelos membros da Escola de Frankfurt, a qual é marcada por uma série de discussões produzidas por teóricos de diferentes áreas (Economia, Ciência Política, Direito, Psicologia, Psicanálise, Filosofia, Comunicação), que marcaram a primeira, segunda e terceira geração da Escola de Frankfurt.

Em síntese, Freitag (1994) aponta três eixos temáticos que desde o início dos trabalhos do Instituto estiveram presentes e até hoje não parecem ter sido esgotados: a) a dialética da razão iluminista e a crítica da ciência; b) a dupla face da cultura e a discussão da indústria cultural; c) a questão do Estado e suas formas de legitimação. Por outro lado, "a atualidade da teoria crítica se evidencia não pela sua capacidade de preservar uma 'escola de pensamento', mas ao contrário, por sua capacidade de renovação, reformulação e autocrítica. Mantendo unicamente seu compromisso com a crítica [...]" (FREITAG, 1994, p. 105).

E como declarou Marx (1997), a revolução inerente às sociedades, a emancipação dos homens constitui um dos pilares fundamentais da teoria crítica, conferindo sentido à teoria em razão da ação da prática transformadora das relações sociais vigentes. Portanto, para a teoria crítica, teoria e prática não devem ser vistas como caminhos opostos; a teoria demonstraria "como as coisas deveriam ser" e a prática "como as coisas são", não sendo esta uma aplicação daquela, mas um conjunto de ideias que orientam a ação (NOBRE, 2010). No Brasil, na área de educação, Paulo Freire traz o pensamento marxista à tona, desnudando os antagonismos da sociedade e da luta de classes no ambiente escolar, o qual é envolto pelo poder - um arquétipo da reprodução da ideologia dominante, conforme denunciaram Bourdieu e Passaron, referente ao sistema educacional francês. Freire (1967) também exalta a teoria da ação antidialógica, onde 
está centrada a "ação dos dominadores" que preferem manter a divisão para poder continuar a opressão e manter a manipulação, deixando as classes menos favorecidas fracas e facilmente manipuladas - uma luta de classe, como descreveu Marx, com embate entre o proletariado e a burguesia e que Freire nomeia de opressor e oprimido.

Consequentemente, a escola acaba funcionando como aparelho ideológico do estado a serviço da manutenção e reprodução do estado, por conseguinte, de uma minoria que detém o poder. Althusser (1970) deixa claro que a condição da produção também requer condições a sua reprodução, como também havia escrito Marx. A escola ensina normas, comportamentos que asseguram a sujeição do indivíduo à ideologia dominante; age, portanto, massivamente por meio da ideologia, diferente da ação repressiva do estado, que tem como uns dos exemplos o exército, a polícia, etc. Contudo, retomando Freire (1967), pode encontrar-se uma saída dessa reprodução, podendo ser através da ação libertadora da educação, de uma "Pedagogia da autonomia", que conferiria humanização e libertação dos homens, não mais calcada em uma "Pedagogia do oprimido". Não se pode ver a educação como um processo neutro e mecanicista; para Freire (1967), a educação é um ato político que deve estar voltado ao conhecimento do educando, para seu universo, para a sua "liberdade". A alfabetização deve vir carregada de significações que traduzam a experiência existencial do educando e não do educador. Freire (1967) destaca que, a concepção do mito da neutralidade da educação leva à negação da natureza política do processo educativo como se fosse um quefazer puro, quando a educação está muito além de uma simples prática de transferência de conhecimento, ela envolve a construção do conhecimento, a educação abarca a problematização das relações do mundo.

Retomando Marx e Engels, Freire caminha na direção de uma práxis, destacando a importância da reflexão e da ação, do agir como mola propulsora da transformação do homemobjeto em homem-sujeito dotado de liberdade, distanciado da ação de domesticação, de uma educação mecânica. É necessário, portanto, a conscientização das massas, que são compostas pelo homem simples, alienado, minimizado e sem consciência dessa minimização. Na verdade, Freire (1967) desvela que essa alienação é intencional, pois as classes dominantes querem apoderar-se das camadas mais ingênuas da sociedade. $\mathrm{O}$ ato transformador dessa realidade, segundo Freire, ocorreria justamente através da consciência da realidade, do homem que vive em relação, está dentro de um contexto não apenas no mundo, mas com o mundo, inserido num processo histórico e cuja relação estabelecida é dialógica, de diálogo. Em suma, "consciência é condicionada pela realidade, a conscientização é um esforço através do qual, ao analisar a prática que realizamos, percebemos em termos críticos o próprio condicionamento a que estamos submetidos" (FREIRE, 2011, p. 139), uma reflexão/conscientização que deve ser acompanhada da ação transformadora do mundo.

\section{CONTRADIÇÕES DO SOCIAL \& BIBLIOTECONOMIA}

O conflito e a desordem são, para Milanesi (1986), elementos centrais à constituição da biblioteca como um centro de informação. A biblioteca em uma visão simplificada constituiria uma coleção de livros organizados para aqueles que buscam ler. A biblioteca, longe dessa estabilidade tem como função, a partir da diversidade dos discursos (contraditórios) e diversificados suportes de informação, desestabilizar a ordem formada por um discurso homogêneo. Esse trabalho de exploração das contradições da ordem é vista como uma atividade política, na qual juntamente com as categorias ordem/desordem é permeada pela ideologia. E, apesar de a biblioteca e a escola constituírem instituições capazes de questionar o discurso dominante, ideologias impostas, as duas acabam se tornando em reprodutoras da hegemonia, reforçando a reprodução cultural e social, indo ao encontro das teorias de Bourdieu e Passeron (1975) e conformando, também, em aparelhos ideológicos do estado, termo cunhado por Althusser (1970).

Nessa direção, Almeida Júnior (1997) também aborda e critica a biblioteca como um 
aparelho ideológico do estado, que não age por meio da repressão, mas por meio da ideologia dominante. Uma ideologia que busca incutir os valores de uma classe, no caso, de uma minoria, que deseja a perpetuação do poder e da ordem que oprime e afasta as classes populares, as quais são em sua maioria "carente de informação", do acesso à informação e dos bens culturais. Assim, a biblioteca é vista como mais um instrumento de poder, sendo utilizada ideologicamente para manter a situação sob controle e, segundo Almeida Júnior (1997) se configura como um obstáculo às classes populares. A biblioteca acaba também excluindo os analfabetos, devido ao privilégio concedido ao suporte da informação escrita, o livro. Com vistas à superação desse modelo, de uma "biblioteca opressora e de dominação", Almeida Júnior (1997) aponta a importância de deslocamento do foco nas letras, na escrita registrada no livro para outras fontes de informação. $O$ autor sinaliza a relevância que deve ser atribuída à construção de registros de informação pela comunidade onde insere a biblioteca, constituindo assim acervos próprios e próximos dos usuários.

A importância dessa ação como instrumento de resistência e de memória foi trabalhado por Freire (1982), que apregoa a importância dos registros dos conhecimentos locais da história, não a oficial, para a formação dos acervos das bibliotecas populares. Milanesi (1986) também aponta o registro da memória como mecanismo de embate da ordem. Ademais, cita como estratégia para superar a reprodução do sistema, a ação do indivíduo que faz uso da informação. Essa ação distancia da ação mecânica, que seria a continuidade da reprodução. Aquela ação desdobraria as possibilidades de problematização, para o pensar, à reflexão, nomeada de ação educativa defendida por Freire. Milanesi (1986) acrescenta a essa visão de ação, a informação, a qual consistiria no insumo da reflexão, de modo que a compreensão da realidade é o primeiro passo para mudá-la. Assim, informação é poder (MILANESI, 1986; ALMEIDA JÚNIOR, 1997). A informação capacita o sujeito do discurso a um questionamento, pois "[..] um indivíduo informado tem maiores condições de fazer prevalecer os seus objetivos e os de sua classe" (MILANESI, 1986, p. 189). A informação é elemento constitutivo do senso crítico, formadora de uma consciência social e política que possa transformar o todo social a partir desse "sujeito crítico" (ALMEIDA JÚNIOR, 1997). Essa concepção da informação como diferencial entre as classes sociais e do poder como posse, que uns possuem e outros não, é associada justamente à concepção marxista de poder (MACHADO, 1999).

Por sua vez, a biblioteca é fundamental no jogo dialético, na superação de categorias como, por exemplo, opressor/oprimido, informados/ desinformados e ordem/desordem. Almeida Júnior (1997) acrescenta que ao lado da informação estão as tecnologias da informação como mais um divisor entre as classes, isto é, classes que detêm informação e acesso versus classes que não detêm acesso à informação e as tecnologias e, por conseguinte, classes que possuem poder versus não possuem o poder. Essa desigualdade constitui o reflexo das desigualdades econômicas e dos bens culturais, assim como "os dominados economicamente também são política e culturalmente e, obviamente, a informação não foge a esse contexto" (ALMEIDA JÚNIOR, 1997, p.11), o que coaduna com a visão da sociedade entremeada pelas relações de produção, de força e poder, segundo Marx.

A perspectiva da biblioteca, como meio de acesso à informação e como possibilidade de questionamento e transformação dos discursos, leva ao entendimento da biblioteca como "instrumento de poder" (MILANESI, 1986). Contudo, o seu paradoxo reside em ter a informação como instrumento de mudança e não conseguir alterar a ordem vigente, vindo a reforçar a ordem e a manutenção do sistema. Segundo Milanesi (1986), outro paradoxo da biblioteca é revelado ao reunir os elementos da indústria cultural como, por exemplo, os livros, os quais são capazes de propiciar uma reflexão que poderá ser contrária a essa indústria, a qual é dirigida para uma cultura de massa, do sistema econômico e estímulo do consumo dos produtos de modo alienante. Essa indústria produz um discurso compatível com a ordem vigente, por isso não vai contra o sistema. Almeida Júnior (1997) acrescenta ainda a questão da produção dos livros que são regidos pelo mercado, já que somente são editados aqueles que a indústria editorial acha conveniente e que lhe garanta o lucro, isto é, o livro precisa ser vendável para ser editado - uma clara relação do mercado editorial com o sistema capitalista. 
Milanesi (1986) traz também o conceito marxista de práxis para reforçar o caráter terreno do pensamento, aliando o discurso teórico à prática, demonstrando a importância de concretizar no âmbito da ação os discursos, ou seja, "o perceber, o refletir, o teorizar deve ter como equilíbrio o agir, a prática" (MILANESI, 1986, p. 137). Brown César (2000), além de demonstrar a influência do funcionalismo estrutural de Luhmman, mais especificamente da teoria dos sistemas, chama a atenção também ao conceito de práxis e do valor do documento, trazendo marcas de uma influência marxista em seu pensamento. Assim, a construção da teoria bibliotecária deve envolver tanto o saber prático quanto o teórico e não promover uma dissociação de um com o outro. Outro autor que também traz elementos para essa conexão com o pensamento marxista é Rojas (2005) para o qual a atividade do bibliotecário deve ser vista como uma ação que se realiza a um fim, direcionada ao interesse de satisfazer as necessidades reais, isto é, as que movem toda a atividade, inclusive as atividades teóricas e filosóficas.

Rojas (2005), ainda sob a influência de Marx, traz o conceito de "relação informacional", que não deve ser visto de modo distante das relações de produção, as quais são processos históricos, relacionados a um grau de desenvolvimento das forças produtivas, independente da vontade do sujeito. Rojas (2005) aborda que a relação informacional surge, independentemente, da vontade do indivíduo, porque no transcurso da vida os seres humanos para poderem existir devem produzir, armazenar, distribuir e criar informações. Retomando Marx, salienta-se a visão do homem como ser produtivo, que precisa gerar aquilo que lhe é necessário para viver, organizandose coletivamente para transformar a natureza e satisfazer suas necessidades. Nessa esteira de pensamento, Rojas (2005) define o homem como um ser informacional, que satisfaz suas necessidades mediante um processo de produção, intervindo na natureza e visto como um transformador do meio social, material e espiritual; o mesmo autor aborda também a atividade bibliotecária como fenômeno de uma sobreestrutura, que descansa sobre as bases das relações informacionais e das formas de comunicação aceitas historicamente.

O usuário, segundo Rojas (2005), sob a influência do pensamento marxista, é visto como construtor do documento, um homem com necessidades de informação que são satisfeitas mediante o uso de documentos, os quais são construídos numa sociedade histórico-concreta e classista. Para Brown César (2000), este autor enfoca os documentos como elementos integrantes do sistema econômico, sendo vistos como mercadorias, pois estão vinculados a um mercado. Os documentos possuem, assim, dois tipos de valor: intrínseco e extrínseco, os quais correspondem, respectivamente, ao valor do conteúdo e do suporte do documento. Um documento se faz valioso ou tendo valor, devido à quantidade incorporada de horas de trabalho socialmente necessária (BROWN CÉSAR, 2000). Além disso, um documento pode ter seu valor agregado a partir de outros elementos adicionados como, por exemplo, notas, índices, glossários, etc. Os sistemas de gestão documental, dos quais fazem parte os documentos, são também responsáveis por agregar valor, devido à representação dos profissionais que fazem parte deles.

Brown César (2000) acrescenta ainda que, os documentos não são elementos naturais, são sim resultados de um processo de transformação da natureza, assim como são distribuídos a partir da ação das unidades administrativas que têm a função de fazê-los chegar ao usuário e, por último, os documentos são "consumidos" quando alguém os assimila cognitivamente, desde o caminho percorrido da produção, distribuição até seu consumo do documento. Sendo assim, como outras mercadorias, os documentos como elementos inseridos num mercado, seguem o fenômeno da "oferta e demanda", bem como seus valores são afetados por fatores externos e internos tais como, a crise econômica, inflação e deflação (BROWN CÉSAR, 2000). Para Rendón Rojas (2005), o documento também, a partir do trabalho do bibliotecário, assume um valor agregado, pois passa a fazer parte da instituição informativa documental, num contexto específico, adquirindo um sentido que não havia anteriormente; assume ainda o valor de uso e de mercado; no primeiro caso, é aquele capaz de satisfazer as necessidades informacionais dos usuários, no segundo se relaciona ao próprio mercado.

Rojas (2005) traz também à discussão a questão da alienação vinculada ao usuário e ao documento. Assim, a superação daria por meio 
do processo de apropriação dos documentos, mas não uma apropriação da ordem da posse material, mas espiritual do conteúdo dos documentos. A biblioteca vista como uma instituição informativa documental permitiria o acesso ao produto social do conhecimento e o acesso ao mundo da informação, que teria como um dos papéis a "desalienação" do homem, o autoconhecimento e a constituição do sujeito, no sentido de existência autêntica do ser, por meio da linguagem, demonstrando a influência filosófica da Fenomenologia no pensamento de Rojas (2005). Esta visão foi criticada por Brown César (2000), já que o documento pode levar à alienação no sentido de que "se lê muito e pensa pouco" e, ainda, sobre a autenticidade: "não se realiza a partir da biblioteca ou de documentos, a tomada de consciência do indivíduo pode ser ocultada por eles, sendo essa saída da inautenticidade a partir da tomada de consciência diante da morte", indo ao encontro de fato do pensamento de Heidegger, visto que a existência humana se dá no tempo e sua essência última é o "ser-para-a-morte". (COLLINS, 2009).

\section{CONSIDERAÇÕES FINAIS}

Karl Marx, um dos autores clássicos das Ciências Sociais e Humanas, fundador ao lado de seu amigo Engels - da corrente de pensamento "contradição do social" -, constitui leitura obrigatória não apenas para compreender a sociedade moderna, mas também a contemporânea. $\mathrm{O}$ pensamento marxista e seus "seguidores", que retomaram as ideias, ampliaram e desenvolveram outras vertentes de pensamento, são também de suma relevância à compreensão dos fenômenos sociais e biblioteconômicos. Os livros analisados revelam aspectos desse arcabouço teórico, discutindo os efeitos das bibliotecas dentro de uma sociedade marcada por interesses antagônicos. A biblioteca não deve e não pode contribuir para essa dicotomia que opera na sociedade, entre aqueles que têm acesso de um lado e os que não têm acesso do outro. A biblioteca é uma instituição a serviço de todos os usuários/cidadãos e não apenas a uma elite que detém o poder e o controle do discurso dominante. Ademais, uma classe privilegiada que já teria mais facilmente o acesso aos bens simbólicos, aos livros e incutido o hábito de leitura, devido ao maior capital cultural e econômico.

Se antes o livro era o instrumento de acesso à cultura, a partir desses autores, pode perceber-se que já não é mais suficiente, considerando que há uma valorização do discurso oral, das histórias narradas, de outros suportes da informação criados, inclusive, pela comunidade onde a biblioteca está inserida. Destaque também atribuído à memória como instrumento de defesa e resistência. O documento constitui, igualmente, na expressão elementar do sistema capitalista, sendo regido pela lei da oferta-demanda, pelo valor de uso e do mercado, o produto de um trabalhador. Além desses apontamentos, o profissional bibliotecário, sujeito da ação não é visto como imparcial ou neutro diante das atividades, ele é regido por interesses e necessidades; o homem é capaz de transformar o próprio homem por meio de seu trabalho, dizia Marx. E a ação é de fundamental importância ao processo de transformação da realidade, sendo a informação e a consciência elementos essenciais na composição de um sujeito crítico e capaz de alterar a ordem; considerando-se a consciência um elemento distintivo do homem frente a outros animais, segundo abordam Marx e Paulo Freire. Ressaltando que, segundo Marx "não é a consciência dos homens que determina o seu ser; é inversamente seu ser social que determina sua consciência".

Em suma, o pensamento revolucionário não se detém no plano das ideias apenas, mas se volta a uma dimensão política, a uma concretização. No plano da Biblioteconomia, essa potência do pensamento rumo a uma ação de transformação, concretização do que está posto e denunciado pelos autores, não pode ser esquecida pelos leitores, bibliotecários, pela sociedade à custa de continuar reproduzindo uma ordem (ou desordem) a que poucos têm acesso, contribuindo ao aumento das desigualdades sociais, principalmente, no que tange aos bens culturais e simbólicos. Nessa direção, em tempo de instabilidade política, de mais desinformação do que informação, reforçase a seguinte reflexão: "a biblioteca não deve se desvincular, nunca, da realidade. Isso significa participar dos acontecimentos sociais, políticos, econômicos, cultuais, etc., tanto como entidade, posicionando-se frente a determinado fato, como também, prestando informações sobre esse fato" (ALMEIDA JÚNIOR, 1997, p. 81). 
Artigo recebido em 22/10/2016 e aceito para publicação em 3/0I/2017

\section{LIBRARY SCIENCE AND SOCIAL CONTRADICTIONS}

ABSTRACT The analysis and discursive relationship of Library Science can be taken from different schools of thought. This work focuses on the discourse of Library Science with the Social Sciences and Humanities, in particular the Marxist and critical thinking. This component named "social contradictions" search reveal the contradictions, conflicts and interests present in society. For this discussion of the discourse Brown César, Rendón Rojas, Almeida Júnior and Milanesi are summoned and tensioned. These authors bring elements in their speeches that enable such a relationship, in whole or in part, in view that the first two authors can have their speeches also associated with other currents of thought such as, "social order" and " building social ", respectively. Understanding of knowledge that make up the discourse of Library Science would allow for greater deeper understanding of this scientific field. Understanding the theoretical characteristics of the authors of Library Science within a wider context such as the Social and Human Sciences, also provides a whitening their inclusion within this field, as well as exposure of the variety and richness of thoughts of Library Science.

Keywords: Library Science. Currents of thought. Social and Human Sciences. Discourse analysis.

\section{REFERÊNCIAS}

ALMEIDA JUNIOR, O. Sociedade e Biblioteconomia. São Paulo: Polis, 1997.

ALTHUSSER, L. Ideologia e aparelhos ideológicos do Estado. Lisboa: Editorial Presença, 1970.

ARAÚJO, C. A. Á. Correntes teóricas da biblioteconomia. Revista Brasileira de Biblioteconomia e Documentação (Online), v. 9, p. 41-58, 2013.

Pensamento marxista na arquivologia, na biblioteconomia, na museologia e na ciência da informação. In: MARQUES, Rodrigo Moreno (Org.). A informação e o conhecimento sob as lentes do marxismo. Rio de Janeiro: Garamond, 2014.

BOTTOMORE, T. B. Dicionário do pensamento marxista. 2.ed. Rio de Janeiro: Zahar, 1988.

BOURDIEU, P.; PASSERON, J. C. A reprodução: elementos para uma teoria do sistema de ensino. Rio de Janeiro: 1975.

BROWN CÉSAR, J. Elementos para uma teoria bibliotecária. México: Escuela Nacional de Biblioteconomia y Archivonomia, 2000.
COLLINS, R. Quatro tradições sociológicas. Petrópolis, RJ: Vozes, 2009.

FOUCAULT, M. A arqueologia do saber. 6. ed. Rio de Janeiro: Forense-Universitária, 2000.

FREIRE, P. A importância do ato de ler: em três artigos que se completam. São Paulo: Autores Associados: Cortez, 1982.

Ação cultural para a liberdade e outros escritos. 11. ed. São Paulo: Paz e Terra, 2011.

Educação como prática da liberdade. Rio de Janeiro: Paz e Terra, 1967.

FREITAG, B. A teoria critica: ontem e hoje. 5.ed. São Paulo: Brasiliense, 1994.

HORKHEIMER, M. Teoria tradicional e teoria crítica. In: HORKHEIMER, Max; ADORNO, Theodor W. Textos escolhidos. São Paulo: nova cultural, 1980. (Os pensadores).

Filosofia e teoria crítica. In: HORKHEIMER, Max; ADORNO, Theodor W. Textos escolhidos. São Paulo: nova cultural, 1980a. (Os pensadores).

MACHADO, R. Microfísica do poder. 14. ed. Rio de Janeiro: Graal, 1999. 
MARX, K. Manifesto do partido comunista. 2 ed. Lisboa: Avante, 1997.

Manuscritos econômico-filosóficos: e outros textos escolhidos. São Paulo: Abril Cultural, 1974. 410 p.

MILANESI, L. Ordenar para desordenar: centros de cultura e bibliotecas públicas. São Paulo: Brasiliense, 1986. 261p.

NOBRE, M. Teoria crítica. Rio de Janeiro: Jorge Zahar, 2011.
OLIVEIRA, M.; QUINTANEIRO, T. K. M. In: QUINTANEIRO, T.; BARBOSA, M. L.; OLIVEIRA, $M$. Um toque de clássicos: Durkheim, Marx e Weber. 2. ed. Belo Horizonte: Ed. UFMG, 2010.

ROJAS, M. Á. R. Bases teóricas y filosóficas de la Bibliotecología. 2 ed. México: UNAM, Centro Universitario de Investigaciones Bibliotecológicas, 2005.

SELL, C. E. Sociologia clássica: Marx, Durkheim e Weber. Petrópolis, RJ: Vozes, 2009. 